\title{
Commentary
}

\section{Cytomegalovirus retinitis: are intraocular devices the answer?}

Martin and associates have recently confirmed the ability of intraocular devices that slowly release ganciclovir to prevent progression of cytomegalovirus (CMV) retinitis. ${ }^{1}$ While there is great enthusiasm for the ability of these devices to control CMV retinitis without systemic toxicity, it is important to consider all factors associated with their use and their long term ability to preserve vision. The ability of intraocular devices to prevent enlargement of lesions must be weighed against the risks of complications arising from the surgical procedure, the risk of new bilateral ocular infection, and the risk of non-ocular CMV disease.

Martin and colleagues have shown that intraocular devices can delay progression of disease for a median of 226 days, which is markedly longer than the 47 day median that was found in a study of intravenous ganciclovir therapy performed by the Studies of Ocular Complications of AIDS (SOCA) Research Group. ${ }^{12}$ Although they are different studies, the times to progression were determined for both by the same fundus photograph reading centre, suggesting that intraocular devices are actually more effective for controlling spread of disease. This longer time to disease progression probably reflects the high drug concentrations achieved at the site of infection and, possibly, release of drug at a steady rate. This study was not designed to address the role of intraocular devices in patients who have failed previous therapy and may have developed drug resistance; current evidence is conflicting regarding their role for such 'salvage' therapy. ${ }^{34}$

Complications of the implantation procedure itself are infrequent, although they can be severe when they do occur. ${ }^{14}$ Real concern, however, has been in three areas retinal detachments, CMV retinitis in the opposite eye, and systemic CMV disease.

Retinal detachments may develop sooner in eyes that are treated with intraocular devices. The SOCA Research Group identified the risk of retinal detachment among patients receiving intravenous ganciclovir to be $27 \%$ at 6 months ${ }^{2}$; in another study with systemic therapy, the median time to detachment was 4 months. ${ }^{5}$ In the study by Martin and associates, retinal detachment or tear occurred in $18 \%$ of eyes, but five of seven retinal detachments occurred sooner than 65 days after implantation of the intraocular device. ${ }^{1}$ An increased rate of early retinal detachments may ultimately be balanced by reduced rates of late retinal detachment; the better control of disease associated with intraocular devices will lead to inactive disease and smaller lesions, both of which are factors associated with fewer detachments. ${ }^{56}$ In long term survivors, however, replacement of devices after they are exhausted of drug may again increase the risk of retinal detachments. ${ }^{4}$ This issue obviously requires additional outcome studies.

It is instructive to compare the risk of developing bilateral ocular infection and systemic CMV disease between treatments. The estimated risk of developing bilateral CMV retinitis at 6 months is $50 \%$ in patients with unilateral disease who are treated with an intraocular device, ${ }^{1}$ whereas the SOCA Research Group found only a $27 \%$ cumulative risk of bilateral disease at 6 months in patients treated with intravenous ganciclovir. ${ }^{2}$

Non-ocular, clinically apparent CMV disease occurred in eight of 26 patients $(31 \%)$ treated with intraocular devices by Martin and associates and, in at least one patient, death was attributed to $\mathrm{CMV}$ infection. ${ }^{1}$ Systemic therapy for CMV infection in both patients with AIDS and those who underwent organ transplant has been shown to decrease the incidence of non-ocular infections, ${ }^{7}$ and appears to prolong patient survival..$^{7-11}$

Are intraocular devices the answer? They do offer an exciting advance in the ability to prevent progression of CMV retinitis lesions. Nevertheless, additional study will be necessary before the overall benefits and costs of this treatment for the long term retention of vision are known, and whether it is truly superior to intravenous therapy in all respects.

Because CMV retinitis, as well as implantation and reimplantation procedures may all cause vision loss by mechanisms other than disease progression, it will be important ultimately to study variables other than time to progression, including visual outcome, when comparing treatments. Whether these devices are best used for new disease, for 'salvage' therapy, or in combination with systemic drug also needs to be determined. A randomised trial comparing various combinations of intraocular devices, oral ganciclovir, and intravenous ganciclovir is currently under way and should help to answer some of these questions. Intraocular devices have the potential of being a much cheaper therapy than intravenous drugs. Nevertheless, more information will be needed about their complications, and the setting in which they will be used, before the true saving associated with their use can be determined. Equally exciting is the prospect of treating a variety of other diseases with this type of therapy by using it to release other drugs, such as corticosteroids or cyclosporin.

UCLA Ocular Inflammatory Disease Center,

ADNAN TUFAII GARY N HOLLAND

Department of Ophthalmology,

UCLA School of Medicine, and

the Jules Stein Eye Institute,

100 Stein Plaza, UCLA

Los Angeles, CA 90095-7003,

USA

1 Martin DF, Parks DJ, Mellow SD, Ferris FL, Walton RC, Remaley NA et al. Treatment of cytomegalovirus retinitis with an intraocular sustainedrelease ganciclovir implant. A randomized controlled clinical trial. Arch Ophthalmol 1994; 112: 1531-9.

2 Studies of Ocular Complications of AIDS (SOCA) Research Group in collaboration with the AIDS Clinical Trials Group (ACTG). Forscarnetganciclovir cytomegalovirus retinitis trial: IV. Visual outcomes. Ophthalmology 1994; 7: 1250-61.

3 Anand R, Nightingale SD, Fish RH, Smith TJ, Ashton P. Control of cytomegalovirus retinitis using sustained release of intraocular ganciclovir. Arch Ophthalmol 1993; 111: 223-7.

4 Morley MG, Duker JS, Ashton P, Robinson MR. Replacing ganciclovir implants. Ophthalmology 1995; 102: 388-92.

5 Jabs DA, Enger C, Haller J, de Bustros S. Retinal detachments in patients with cytomegalovirus retinitis. Arch Ophthalmol 1991; 109: 794-9.

6 Freeman WR, Friedberg DN, Berry C, Quiceno JI, Behette M, Fullerton SC, et al. Risk factors for development of rhegmatogenous retinal detachment in patients with cytomegalovirus retinitis. Am $\mathcal{f}$ Ophthalmol 1993; 116: 713-20. 
7 Morinelli EN, Dugel PU, Lee M, Klatt EC, Rao NA. Opportunistic intraocular infections in AIDS. Trans Am Ophthalmol Soc 1992; 90: intraocular

8 Holland GN, Sison RF, Jatulis DE, Haslop MG, Sakamoto MJ, Wheeler NC. Survival of patients with the acquired immune deficiency syndrome after development of cytomegalovirus retinopathy. UCLA CMV Retinopathy Study Group. Ophthalmology 1990; 97: 204-11.

9 Jacobson MA, Causey D, Polsky B, Hardy D, Chown M, Davis R, et al. A dose-ranging study of daily maintenance intravenous foscarnet thetapy for cytomegalovirus retinitis in AIDS. I Infect Dis 1993; 168: 444-8.

10 Goodrich JM, Mori M, Gleaves CA, Du Mond C, Cays M, Ebeling DF, et al. Early treatment with ganciclovir to prevent cytomegalovirus disease after allogeneic bone marrow transplantation. $N$ Engl $\mathcal{F}$ Med 1991; 325: $1601-7$.

11 Singh N, Yu VL, Mieles L, Wagener MM, Miner RC, Gayowski T. High-dose acyclovir compared with short-course preemptive ganciclovir therapy to prevent cytomegalovirus disease in liver transplant recipients. A randomized trial. Ann Intern Med 1994; 120: 375-81. 